\title{
Seasonal Prevalence and Antibiogram Studies of Bovine Mastitis in Southern Haryana
}

\author{
Jinu Manoj ${ }^{1 *}$ and Manoj Kumar Singh ${ }^{2}$ \\ ${ }^{1}$ College Central Laboratory, College of Veterinary Sciences, Lala Lajpat Rai University of Veterinary E Animal Sciences, \\ Hisar, Haryana, INDIA \\ ${ }^{2}$ Department of Livestock Production and Management, College of Veterinary and Animal Sciences, SVPUAT, Meerut, \\ U.P., INDIA \\ *Corresponding author: J Manoj; E-mail: drjinumanoj@gmail.com
}

Received: 17 Sept., 2020

Revised: 26 Nov., 2020

Accepted: 10 Dec., 2020

\begin{abstract}
Mastitis in bovines causes huge economical loss to the dairy industry. It affects the public health due to the transmission of pathogenic bacteria and the toxins produced by them through the food chain. The timely diagnosis of subclinical mastitis (SCM) and its proper treatment based on antibiogram have significant impact on reducing the economical loss to the dairy farmers. Therefore the present study was conducted to find out the prevalence and antibiogram pattern of the mastitis causing bacteria in Southern Haryana. A total prevalence rate of $65.79 \%$ was observed for subclinical mastitis in Southern Haryana by the screening test. The highest prevalence was observed in winter (59.49\%), followed by rainy season $(69.61 \%)$ and cattle were found as more susceptible to SCM when compared to buffaloes. The major Gram negative pathogens isolated were belonged to $E$. coli, followed by Klebsiella species and Pseudomonas species, the common organisms responsible for environmental mastitis. The antibiogram patterns of the isolates were also studied and the maximum sensitive antibiotic against mastitis was found as Chloramphenicol, followed by Enrofloxacin, Amikacin and Ampicillin. The most resistant antibiotics in the study area was found as Ceftizoxime followed by Amoxicillin as these antibiotics were frequently and indiscriminately used for the treatment of mastitis in the study area without subjecting to in vitro antibiotic sensitive test. This emphasis the need of awareness among dairy farmers regarding the hygienic managemental practices to be followed at farm level as well as necessity of conducting antibiotic sensitivity test for the treatment.
\end{abstract}

\section{HIGHLIGHTS}

(0) A total prevalence of mastitis observed was $65.79 \%$.

(o The most resistant antibiotics were Ceftizoxime and Amoxicillin.

(0 The most sensitive antibiotics were Chloramphenicol and Enrofloxacin.

Keywords: Antibiogram, Haryana, Mastitis, Prevalence, Seasonal

Mastitis the potentially fatal udder tissue infection is the most common disease in dairy animals. It usually occurs due to the inflammatory response to bacterial invasion of the teat canal. It can also occur as a result of chemical, mechanical or thermal injury to the udder (Akhoon et al., 2015). It affects the public health due to the transmission of pathogenic bacteria and their toxins through the food chain (Argaw, 2016; Shaheen et al., 2016; Hameed et al., 2007). The prevalence of subclinical mastitis
(SCM) is more prevalent than clinical mastitis (Sharma et al., 2012). Meta analysis revealed $29-45 \%$ increased prevalence of subclinical mastitis during 2011 to 2016 (Krishnamoorthy et al., 2017). The subclinical mastitis lacks visible inflammatory changes initially and for the

How to cite this article: Manoj, J. and Singh, M.K. (2020). Seasona Prevalence and Antibiogram Studies of Bovine Mastitis in Southern Haryana. J. Anim. Res., 10(6): 1037-1042. Source of Support: None; Conflict of Interest: None क्) 
detection of it, the laboratory examination is necessary. Mastitis in bovines causes huge economical loss to the livestock industry globally and affects international trade of milk and milk products (Shaheen et al., 2016). The economical loss due to mastitis in Indian conditions is also available (Devi and Dutta, 2018). The sub clinically affected animals can act as continuous source of infection to other animals also (Dasohari et al., 2017). If untreated, SCM leads eventually to clinical mastitis and will be difficult to cure completely. The indiscriminate use of antibiotics for the treatment of mastitis without checking the in vitro sensitivity pattern leads to treatment failure as well as development of antibiotic resistance in addition to the financial burden (Shaheen et al., 2016). Antibiotic resistance among mastitogens is well reported in India (Tufani et al., 2012; Charaya et al., 2013; Akhoon et al., 2015; Chandrasekharan et al., 2015; Das et al., 2017). The monitoring of antibiotic resistance in livestock is recommended by OIE and WHO recommends a rational and judicious use of antibiotics in public domain (Dougnon et al., 2020). The antibiotic resistance a global concern can be minimised by the discriminate as well as proper monitoring of its use in livestock sector. The timely diagnosis of subclinical mastitis and its proper treatment based on antibiogram have significant impact on reducing the economical loss to the dairy farmers (Argaw, 2016). Therefore, the present study was conducted to find out the prevalence and antibiogram pattern of the mastitis causing bacteria in Southern Haryana.

\section{MATERIALS AND METHODS}

\section{Milk Samples}

This one year study was conducted from June 2018 to May 2019. A total of 6738 milk samples brought to the Disease Investigation Laboratory, Lala Lajpat Rai University of Veterinary and Animal Sciences, Mahendragarh, Haryana were examined for subclinical mastitis. Out of these, 5196 and 1542 samples were from buffaloes and cows, respectively. The study period was divided into four season's viz., summer, winter, spring/autumn and rainy (Table 1).

\section{Screening test}

The milk samples were screened for subclinical mastitis by modified whiteside test using $4 \%$ sodium hydroxide solution. The nature of coagulation and viscosity formed after adding the reagent with equal amount of milk was noted for diagnosing the subclinical mastitis and the severity of the infection.

\section{Phenotypical characterization}

A total of 214 milk samples (107 samples each from both the species of study) which were found as positive for subclinical mastitis by the screening test were further subjected to microbiological analysis (Quinn et al., 2011). The isolation and identification of Gram negative organisms were attempted from these samples. Briefly, the positive milk samples were streaked onto MacConkey Lactose agar and incubated overnight at $37^{\circ} \mathrm{C}$ aerobically. The bacterial colonies developed after the incubation was identified on the basis of morphological and phenotypical features such as colony size, shape, colour development and biochemical characteristics. Gram negative bacteria were identified by diverse biochemical reactions such as IMViC test, urease test, $\mathrm{H}_{2} \mathrm{~S}$ production and fermentation of sugars. Gram staining of the pure colonies was also performed using Gram's stain kit K001L (HiMedia Lab. Pvt. Ltd., Mumbai).

\section{Antibiotic sensitivity studies}

The antibiogram patterns of the isolates were also studied as per the standard protocol (Kirby-Bauer's disc diffusion technique) in brain heart infusion agar using guidelines of CLSI (Bauer et al., 1966). A total of 12 antibiotic discs were used (Table 2) to study the susceptibility pattern of the Gram negative mastitogens. The sensitivity and the resistance patterns of the organism were recorded by comparing the diameter of growth inhibition zone developed with the zone diameter interpretation chart provided by the manufacturer (HiMedia Lab. Pvt. Ltd., Mumbai) of the antibiotic discs.

\section{RESULTS AND DISCUSSION}

\section{Prevalence rate}

In the present study a total prevalence rate of $65.79 \%$ was observed for subclinical mastitis in Southern 
Haryana by the screening test. Among these, 3271 and 1162 samples were found as positive from buffaloes and cattle, respectively with $62.95 \%$ and $75.35 \%$ species-wise prevalence. The cows are more prevalent for mastitis than buffaloes (Sharma et al., 2012; Devi and Dutta, 2018). The season wise prevalence of SCM is depicted in Table 1 with highest prevalence observed in winter $(59.49 \%)$, followed by rainy season $(69.61 \%)$.

Table 1: Milk samples examined (Season-wise) for mastitis during 2018-2019

\begin{tabular}{lllll}
\hline Season* & Species & $\begin{array}{l}\text { No. of } \\
\text { samples } \\
\text { examined }\end{array}$ & $\begin{array}{l}\text { No. of } \\
\text { samples } \\
\text { positive }\end{array}$ & $\begin{array}{l}\text { Prevalence } \\
\text { (\%) }\end{array}$ \\
\hline \multirow{4}{*}{ Rainy } & Buffalo & 1525 & 1004 & 65.83 \\
& Cattle & 670 & 524 & 78.20 \\
& Total & 2195 & 1528 & 69.61 \\
Spring/ & Buffalo & 1516 & 868 & 57.25 \\
Autumn & Cattle & 291 & 207 & 71.13 \\
& Total & $\mathbf{1 8 0 7}$ & $\mathbf{1 0 7 5}$ & $\mathbf{5 9 . 4 9}$ \\
& Buffalo & 1606 & 1131 & 70.42 \\
Winter & Cattle & 254 & 198 & 77.95 \\
& Total & $\mathbf{1 8 6 0}$ & $\mathbf{1 3 2 9}$ & $\mathbf{7 1 . 4 5}$ \\
& Buffalo & 549 & 268 & 48.81 \\
Summer & Cattle & 327 & 233 & 71.25 \\
& Total & $\mathbf{8 7 6}$ & $\mathbf{5 0 1}$ & $\mathbf{5 7 . 1 9}$ \\
& Buffalo & 5196 & 3271 & 62.95 \\
Total & Cattle & 1542 & 1162 & 75.35 \\
& Total & $\mathbf{6 7 3 8}$ & $\mathbf{4 4 3 3}$ & 65.79 \\
\hline
\end{tabular}

"Rainy-July, August, September; Spring/Autumn-October, November, March; Winter-December, January, February; SummerApril, May, June

The prevalence of subclinical mastitis reported varied widely with respect to geography, agro climatic conditions and management practices of different area. Palanivel et al. (2008) reported highest occurrence of mastitis in summer from Tamilnadu, while Kurjogi and Kaliwal (2014) from Karnataka reported highest prevalence during monsoon season followed by winter. Tufani et al. (2012) found highest mastitis prevalence in spring season followed by winter. Prevalence rate of mastitis varies from place to place, herd to herd and country to country (Devi and Dutta, 2018). Various researchers across the State reported different prevalence rates of SCM in their studies. Charaya et al. (2018) and Pankaj et al. (2012) reported 33.76\% and $64.21 \%$ prevalence of subclinical mastitis in buffaloes and cows respectively from Hisar, Haryana. Jhambh et al. (2017) found $31.79 \%$ prevalence of SCM in buffaloes from an organized farm located in Haryana. Bhanot et al. (2012) reported a prevalence rate of $85.30 \%$ in cows and $78.1 \%$ in buffaloes, respectively in Eastern Haryana. Kumar and Sharma (2002) reported 59.86\% and 66.27\% prevalence of SCM in cows and buffaloes, respectively from Hisar, Haryana. The prevalence rate of SCM from various parts of India also reported. Swami et al. (2017) reported a prevalence rate of $35 \%$ in cows and $28.33 \%$ in buffaloes, respectively from Latore, Maharashtra. Gogoi et al. (2017) reported a prevalence rate of $19.56 \%$ in cows from Assam, while Javia et al. (2018) reported 34.29\% of SCM from Junagarh, Gujarat. Bhaghel et al. (2018) from Mhow, Madhya Pradesh, Sharma et al. (2007) from Chatissgarh and Dasohar et al. (2017) from Hyderabad, Telangana recorded $43.6 \%, 66 \%$ and $66.18 \%$ positivity of $\mathrm{SCM}$ in their studies, respectively. Kurjogi and Kaliwal (2014) recorded 46\% prevalence from Karnataka. Kumari et al. (2018) reviewed about subclinical mastitis of cattle with emphasis on prevalence, risk factors and economical losses in various States of India.

In this study, a total of 67 Gram negative bacterial isolates were isolated from the mastitic milk samples of buffaloes, while only 43 Gram negative bacterial isolates were obtained from cows. The major pathogens isolated from buffaloes belonged to E. coli (50.74\%), followed by Klebsiella sp. (40.29\%) and Pseudomonas sp. (5.97\%). One isolate of Proteus sp. and Salmonella sp. was also found from mastitic buffaloes. In case of cows, 19 isolates were of E. coli $(57.57 \%$ ), while Klebsiella sp. was of $33.33 \%$ and Pseudomonas sp. was of $9.09 \%$. The major pathogens for environmental mastitis are E. coli, Klebsiella and Proteus (Shaheen et al., 2016). The presence of pathogens from the infection depends on several risk factors such as quality of managemental practices followed at farm and milking level (Argaw, 2016). Animal which are frequently exposed to constant soiling of udder due to improper housing and hygienic conditions are more likely to have mastitis caused by environmental pathogens like E. coli (Sharma et al., 2007; Akhoon et al., 2015). 


\section{Antibiotic sensitivity studies}

The in vitro antibiotic sensitivity test data obtained were expressed in percentage of sensitivity and resistance against Gram negative bacterial isolates (Fig. 1).

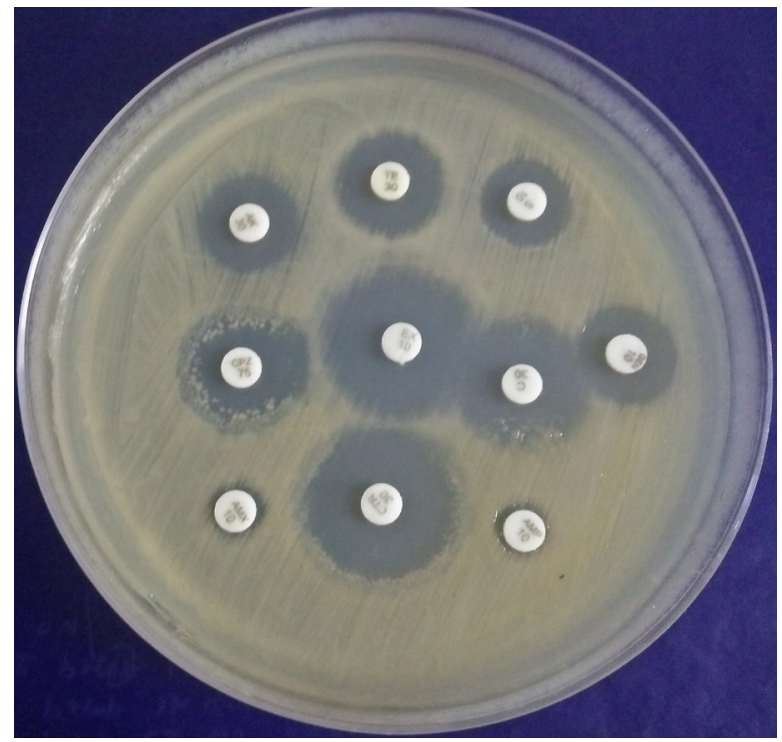

Fig. 1: Antibiotic Sensitivity Test

In the present investigation, the maximum sensitive antibiotic against subclinical mastitis in buffaloes from Southern Haryana was found as Chloramphenicol $(65.63 \%)$ followed by Enrofloxacin (56.25\%), Amikacin (47.10\%) and Ampicillin (36.73\%) (Table 2). The most resistant antibiotics against the mastitogens in the study area were found as Ceftizoxime $(66.37 \%)$, followed by Amoxicillin (58.10\%) and Ceftriaxone (39.02\%). The antibiotics, Cefoperazone (47.35\%), Amoxyclav (52.23\%), Oxytetracycline (44.93\%), Gentamicin (42.52\%) and Streptomycin $(38.51 \%)$ were found as intermediate in susceptibility in majority of the mastitic cases from buffaloes. The studies reported from various States of India gives an indication about the antibiotic resistance pattern of subclinical mastistis across the country. Akhoon et al. (2015) found cent percentage sensitivity to Gentamicin, while Ampicillin and Amoxicillin showed complete resistance in their studies from Kashmir. Sharma et al. (2007) also reported highest sensitivity to Gentamicin by E. coli isolates. Chandrasekaran et al. (2015) reported more sensitivity to Enrofloxacin and highest resistance to penicillin followed by Amoxicillin against E. coli isolates from Tamil Nadu. Bhanot et al. (2012) observed
Enrofloxacin as most sensitive drug at eastern Haryana, while Bhat et al. (2017) from Jammu reported Enrofloxacin and Gentamicin as most sensitive drug against $E$. coli and Penicillin as the least effective antibiotic.

Table 2: In vitro antibiotic sensitivity of Gram negative isolates from cases of mastitis in buffaloes

\begin{tabular}{lllll}
\hline $\begin{array}{l}\text { Sl. } \\
\text { No. }\end{array}$ & Antibiotics & $\begin{array}{l}\text { Sensitive } \\
(\mathbf{\%})\end{array}$ & $\begin{array}{l}\text { Intermediate } \\
(\mathbf{\%})\end{array}$ & $\begin{array}{l}\text { Resistance } \\
(\mathbf{\%})\end{array}$ \\
\hline 1 & Chloramphenicol & 65.63 & 18.75 & 15.62 \\
2 & Enrofloxacin & 56.25 & 22.87 & 21.88 \\
3 & Amikacin & 47.10 & 36.33 & 16.57 \\
4 & Ampicillin & 36.73 & 42.04 & 21.23 \\
5 & Cefoperazone & 30.13 & 47.35 & 22.52 \\
6 & Amoxyclav & 29.40 & 52.23 & 18.37 \\
7 & Oxytetracycline & 32.79 & 44.93 & 22.28 \\
8 & Gentamicin & 28.93 & 42.52 & 28.55 \\
9 & Streptomycin & 29.17 & 38.51 & 32.32 \\
10 & Ceftriaxone & 21.16 & 33.82 & 39.02 \\
11 & Amoxicillin & 13.28 & 28.62 & 58.10 \\
12 & Ceftizoxime & 15.46 & 18.17 & 66.37 \\
\hline
\end{tabular}

Table 3: In vitro antibiotic sensitivity of Gram negative isolates from cases of mastitis in cows

\begin{tabular}{lllll}
\hline $\begin{array}{l}\text { Sl. } \\
\text { No. }\end{array}$ & Antibiotics & $\begin{array}{l}\text { Sensitive } \\
(\%)\end{array}$ & $\begin{array}{l}\text { Intermediate } \\
(\%)\end{array}$ & $\begin{array}{l}\text { Resistance } \\
(\%)\end{array}$ \\
\hline 1 & Chloramphenicol & 71.62 & 14.97 & 14.01 \\
2 & Enrofloxacin & 62.61 & 17.77 & 19.62 \\
3 & Amikacin & 51.40 & 28.97 & 19.63 \\
4 & Ampicillin & 42.05 & 31.77 & 26.18 \\
5 & Cefoperazone & 34.57 & 51.40 & 14.03 \\
6 & Amoxyclav & 33.64 & 45.79 & 20.57 \\
7 & Oxytetracycline & 30.08 & 37.99 & 31.93 \\
8 & Gentamicin & 29.90 & 32.05 & 38.05 \\
9 & Streptomycin & 27.10 & 26.44 & 46.46 \\
10 & Ceftriaxone & 26.16 & 28.05 & 45.79 \\
11 & Amoxicillin & 25.33 & 30.84 & 43.93 \\
12 & Ceftizoxime & 23.36 & 28.98 & 47.66 \\
\hline
\end{tabular}

Almost similar antibiotic sensitivity trend was observed in mastitits from cattle too (Table 3), eventhough the percentage of sensitivity was a little higher among them. In case of cattle, the most sensitivity was found for Chloramphenicol $(71.62 \%)$ followed by Enrofloxacin (62.61\%), Amikacin (51.40\%) and Ampicillin (42.05\%) 
with highest resistance for Ceftizoxime (47.66\%) followed by Streptomycin (46.46\%), Ceftriaxone (45.79\%) and Amoxicillin (43.93\%). In this study, the maximum sensitivity was observed for Amphenicol group of antibiotics, followed by Fluoroquinolones. It was further observed from the history of cases that the most resistant antibiotics found in this study were in field use, frequently and indiscriminately, since a long time for the treatment of mastitis in the study area, without subjecting to in vitro antibiotic sensitive test. Several researchers reported similar problems in case of bovine mastitis across the country, which leads to antibiotic resistance eventually (Awandkar et al., 2013; Akhoon et al., 2015; Shaheen et al., 2016; Bhat et al., 2017).

\section{CONCLUSION}

Mastitis become a concern for dairy farmers, dairy processors, consumers and society due to its high incidences, production losses, milk quality, animal welfare, antimicrobial resistance and residue issues. The presence of environmental pathogens in this study strongly recommends the need for hygienic management measures to be followed at farm level to prevent environmental mastitis. The study emphasis the needs of investigation of mastitis epidemiology as well as the awareness among dairy farmers regarding the necessity of conducting antibiotic sensitivity test also. This in turn, will increase the income of dairy farmer through reduced treatment cost, ensuring better livestock welfare and increased milk production with premium benefits in the dairy industry.

\section{REFERENCES}

Akhoon, Z.A., Peer, F.U. and Nazir, A. 2015. Epidemiology of mastitis in Kashmir valley. Indian J. Comp. Microbiol. Immunol. Infect. Dis., 36: 43-45.

Argaw, A. 2016. Review on epidemiology of clinical and subclinical mastitis on dairy cows. Food Sci. Qual. Manag., 52: $56-65$

Awandkar, S.P., Bhikane, A.U. and Kulkarni, M.B. 2013. Antibiotic resistance trends in clinical bovine mastitis. Biolife., 1: 139-143.

Baghel, A., Chhabra, D., Sharda, R., Shukla, S., Audarya, S., Sikrodia, R. and Gangil, R. 2018. Isolation of Staphylococcus from bovine mastitis and their antibiotic sensitivity pattern. Indian J. Vet. Sci. Biotechnol., 13: 49-52.
Bauer, A.W., Kieby, W.M.M., Shrenis, J.C. and Turck, M. 1966. Antibiotic susceptibity testing by a standardized single disc diffusion method. American J. Clin. Pathol., 45: 453-496.

Bhanot, V., Chaudhri, S.S., Bisla, R.S. and Singh, H. 2012. Retrospective study on prevalence and antibiogram of mastitis in cows and buffaloes of eastern Haryana. Indian J. Anim. Res., 46:160-163.

Bhat, A.M., Soodan, J.S., Singh, R., Dhobi, I.A., Hussain, T., Dar, M.Y. and Mir, M. 2017. Incidence of bovine clinical mastitis in Jammu region and antibiogram of isolated pathogens. Vet. World., 10: 984-989.

Chandrasekaran, D., Nambi, A.P., Thirunavukkarasu, P.S., Venkatesan, P., Tirumurugaan, K.G. and Vairamuthu, S. 2015. Incidence of resistant mastitis in dairy cows in Tamil Nadu, India. J. Appl. Nat. Sci., 7: 304-308

Charaya, G., Sharma, A., Singh, M., Tiwari, S., Pankaj and Kumar, A. 2013. Subclinical mastitis at an organised farm: prevalence, etiology and antibiogram. Haryana Vet., 52: 3032.

Das, A., Guha, C., Biswas, U., Jana, P.S., Chatterjee, A. and Samanta, I. 2017. Detection of emerging antibiotic resistance in bacteria isolated from subclinical mastitis in cattle in West Bengal, Vet. World., 10: 517-520.

Dasohari, A., Somasani, A., Nagaraj, P and Reddy G. A. 2017. Epidemiological studies of subclinical mastitis in cows in and around Hyderabad. Pharma Innov. J., 6: 975-979.

Devi, M. and Dutta, J.B. 2018. Incidence of bovine subclinical mastitis in organized and unorganized farms based on somatic cell count. Int. J. Chem. Stud., 6: 1399-1403.

Dougnon, V., Chabi, Y., Koudokpon, H., Agbankpe, J., Sefounon, R., Alle, D., Bankole, H. and Baba-Moussa, L. 2020. Prescription of antibiotics as a source of emerging antibiotic resistance: Knowledge, attitudes, and practices of medical staff in the Dassa-Glazoue and Savalou-Bante's health zones (Benin, West Africa). Int. J. One Health., 6: 34-40.

Gogoi, S.M., Tamuly, U.R., Khuman, L.S., Saikia, G.K. and Bordoloi, G. 2017. Prevalence of sub clinical mastitis in areas around Lakhimpur town of Assam. Int. J. Agri. Sci. Res., 7: 501-508.

Hameed, K.G.A., Sender, G. and Korwin-Kossakowaska, A. 2007. Public health hazard due to mastitis. Anim. Sci. Pap. Report., 25: 73-85.

Javia, B., Purohit, J., Mathapati, B., Barad, D., Savsani, H., Ghodasara, S., Kalariya, V., Patel, U. and Nimavat, V. 2018. Molecular detection and antimicrobial resistance pattern of Staphylococci isolated from clinical and subclinical bovine mastitis. Indian J. Vet. Sci. Biotechnol., 14: 13-16.

Jhambh, R., Dimri, U., Gopala Krishnan, A., Singh, M. and Chhabra, R. 2017. Prevalence and risk factors of subclinical 
mastitis in buffaloes at an organized dairy farm in western Haryana. Haryana Vet., 56: 189-193.

Krishnamoorthy, P., Suresh, K.P., Saha, S., Govindaraj, G., Shome, B.R. and Roy, P. 2017. Meta analysis of prevalence of subclinical and clinical mastitis, major mastitis pathogens in dairy cattle in India. Int. J. Current Microbiol. Appl. Sci., 6: $1214-1234$.

Kumar, R. and Sharma, A. 2002. Prevalence, etiology and antibiogram of mastitis in cows and buffaloes in Hisar, Haryana. Indian J. Anim. Sci. 72: 361-363.

Kumari, T., Bhakat, C. and Choudhary, R.K. 2018. A review on sub clinical mastitis in dairy cattle, Int. J. Pure App. Biosci., 6: 1291-1299.

Kurjogi, M.M. and Kaliwal, B.B. 2014. Epidemiology of bovine mastitis in cows of Dharwad district. Int. Schol. Res. Notice., 2014: 1-9. Article ID 968076.

Pankaj, Sharma, A., Chhabra, R. and Sindhu, N. 2012. Prevalence of sub clinical mastitis in cows: its etiology and antibiogram. Indian J. Anim. Res., 46: 348-353.

Quinn, P.J., Markey, B.K., Leonard, F.C., Fitz Patrick, E.S., Fanning, S. and Hartigan, P.J. 2011. Veterinary Microbiology and Microbial Diseases, $2^{\text {nd }}$ Ed., Wiley Blackwell, John Wiley \& Sons Ltd, West Sussex, UK, pp. 115-292.
Shaheen, M., Tantary, H.A. and Nabi, S.U. 2016. A treatise on bovine mastitis: disease and disease economics, etiological basis, risk factors, impact on human health, therapeutic management, prevention and control strategy. J. Adv. Dairy Res., 4: 150.

Sharma, N., Maiti, S.K. and Sharma K.K. 2007. Prevalence, etiology and antibiogram of microorganisms associated with sub-clinical mastitis in buffaloes in Durg, Chhattisgarh State (India). Int. J. Dairy Sci., 2: 145-151.

Sharma, N., Rho, G.J., Hong, Y.H., Kang, T.Y., Lee, H.K., Hur, T. and Jeong, D.K. 2012. Bovine mastitis: An Asian perspective. Asian J. Anim. Vet. Adv., 7: 454-476.

Sharma, A., Chhabra, R., Singh, M. and Charaya, G. 2018. Prevalence, etiology and antibiogram of bacterial isolates recovered from mastitis of buffaloes. Buffalo Bulletin., 37: 313-320.

Swami, S.V., Patil, R.A. and Gadekar, S.D. 2017. Studies on prevalence of subclinical mastitis in dairy animals. $J$. Entomol. Zool. Stud., 5: 1297-1300.

Tufani, N.A., Makhdoomi, D. M. and Hafiz, A. 2012. Epidemiology and therapeutic management of bovine mastitis. Indian J. Anim. Res., 46: 148-151. 